\title{
Structural systematics of some metal complexes with 4,5-diazafluoren-9-one
}

\author{
ABHIJIT PAL $^{\mathrm{a}}$, BHASKAR BISWAS ${ }^{\mathrm{a}, \mathrm{b}}$, MERRY MITRA ${ }^{\mathrm{a}}$, CHANDRA SHEKHAR PUROHIT $^{\mathrm{c}}$, \\ CHIA-HER LIN ${ }^{\mathrm{d}}$ and RAJARSHI GHOSH ${ }^{\mathrm{a}, *}$ \\ a Department of Chemistry, The University of Burdwan, Burdwan 713 104, India \\ ${ }^{b}$ Department of Chemistry, Raghunathpur College, Purulia 723 133, India \\ ${ }^{\mathrm{c}}$ Department of Chemical Sciences, National Institute of Science Education and Research, \\ Bhubaneswar 751 005, India \\ ${ }^{\mathrm{d} D e p a r t m e n t ~ o f ~ C h e m i s t r y, ~ C h u n g ~ Y u a n ~ C h r i s t i a n ~ U n i v e r s i t y, ~ C h u n g ~ L i ~ 32023, ~ T a i w a n, ~ R e p u b l i c ~ o f ~ C h i n a ~}$ \\ e-mail: rajarshi_chem@yahoo.co.in
}

MS received 25 September 2013; revised 20 January 2014; accepted 27 January 2014

\begin{abstract}
Synthesis and X-ray structural characterization of three complexes of type cis-[M(dafone $\left.)_{2}(\mathrm{NCS})_{2}\right]$ $(\mathrm{M}=\mathrm{Co}(\mathrm{II}), \mathbf{1} ; \mathrm{Ni}(\mathrm{II}), \mathbf{2} ; \mathrm{Zn}(\mathrm{II}), \mathbf{3}$; dafone $=4,5$-diazafluoren-9-one $)$ and a polymer cis-[Cd(dafone)(NCS $\left.)_{2}\right]_{\mathrm{n}}$ (4) have been reported. Each of the four complexes is crystallized in orthorhombic crystal system. Structural study reveals that each metal(II) centre in the four complexes adopts distorted octahedral geometry with $\mathrm{MN}_{6}$ chromophore in 1-3 and $\mathrm{MN}_{4} \mathrm{~S}_{2}$ chromophore in 4 . The room temperature steady-state fluorescent intensity of dafone in dimethyl formamide at $402 \mathrm{~nm}$ is found to be quenched in these reported dafone complexes (1-4).
\end{abstract}

Keywords. Transition metal ions; imine ligand; crystal structure; fluorescence.

\section{Introduction}

Design and synthesis of coordination compounds of different nuclearity are being continued ${ }^{1,2}$ because of their various synthetic, structural and physicochemical features. Different diimine ligands are being used ${ }^{3,4}$ in this direction because of synthetic accessibilities and spectroscopic properties of their own and the complexes synthesized there from. Common bipyridyls with diimine functions such as 2,2'-bipyridine (bpy), 1,10-phenanthroline (phen), etc. and their derivatives are often used ${ }^{3,4}$ to synthesize variety of complexes with different nuclearity and interesting properties. The ambidentate thiocyanates, having soft sulphur and hard nitrogen donor centres, show a number of coordination motifs ${ }^{5}$ towards metal ions exhibiting different molecular structures with different dimensionalities. ${ }^{5}$ In recent times a number of transition and innertransition metal complexes from diimine donors as a part of Schiff base ligand had been reported by our group. ${ }^{6}$ In this study, we have used 4,5-diazafluoren-9-one

*For correspondence (dafone) ${ }^{7}$ the diimine with larger chelate bite than the bpy and phen (free dafone: $3.05 \AA$, bpy: $2.62 \AA$, phen: $2.64 \AA),{ }^{8}$ oxidized from 1,10-phenanthroline to synthesize a series of complexes with $\mathrm{Co}(\mathrm{NCS})_{2}(\mathbf{1}), \mathrm{Ni}(\mathrm{NCS})_{2}$ (2), ${ }^{8 a, 8 b} \mathrm{Zn}(\mathrm{NCS})_{2}(3)$ and $\mathrm{Cd}(\mathrm{NCS})_{2}$ (4). Interestingly, the $\mathrm{X}$-ray structural analyses in each case reveal that all these are cis complexes and the mononuclear cis moiety of $\mathrm{Cd}(\mathrm{NCS})_{2}$ forms polymer because of the soft-hard nature of the thiocyanate. The complexes also show room temperature steady-state fluorescence behaviour. Though a few of the $\mathrm{Cu}$ (II) ${ }^{8 \mathrm{a}, 8 \mathrm{8b}, 9} \mathrm{Ni}(\mathrm{II}),{ }^{8 \mathrm{a}, 8 \mathrm{~b}}$ $\mathrm{Zn}(\mathrm{II}),{ }^{8 \mathrm{c}} \mathrm{Ru}(\mathrm{II})^{10}$ and $\mathrm{Pt}(\mathrm{II})^{8 \mathrm{c}}$ complexes of dafone are reported in literature, here we have tried to establish the structural systematics and photophysical behaviour of a group of new complexes including a reported one. ${ }^{8 a, 8 b}$

\section{Experimental}

\subsection{Preparation of the complexes $\mathbf{1 - 4}$}

2.1a Chemicals, solvents and starting materials: High purity 1,10 phenanthroline (E Merck, India), potassium permanganate (E Merck, India), potassium 
hydroxide (E Merck, India), cobalt(II) perchlorate hexahydrate (E Merck, India), nickel(II) nitrate hexahydrate (E Merck, India), zinc(II) acetate dihydrate (E Merck, India) and cadmium(II) acetate dihydrate (E Merck, India) and all other solvents were purchased from the respective companies and used as received. Solvents were dried according to standard procedure and distilled prior to use.

(Caution! Perchlorate salts of metal ions are potentially explosive, especially in the presence of organic ligands. Only a small amount of material should be prepared and it should be handled with care.)

2.1b Preparation of $L$ and 1-4: The ligand dafone was prepared using a reported method. ${ }^{10}$ The ligand was characterized by X-ray crystallography (figure 1, table 1).

Dafone $(0.364 \mathrm{~g}, 2 \mathrm{mmol})$ in methanol was added slowly to the methanolic solution of $\mathrm{Co}\left(\mathrm{ClO}_{4}\right)_{2}$ $(0.361 \mathrm{~g}, 1 \mathrm{mmol})$ resulting in a light brown coloured solution which was intensified on gradual addition of $\mathrm{NH}_{4} \mathrm{NCS}(0.152 \mathrm{~g}, 2 \mathrm{mmol})$. The final reaction solution was kept in open air for slow evaporation. Light brown crystals appeared after about a week. Yield: (based on metal salt) $0.388 \mathrm{~g}(72.00 \%)$. Anal. Calc. for $\mathrm{C}_{24} \mathrm{H}_{12} \mathrm{~N}_{6} \mathrm{O}_{2} \mathrm{~S}_{2} \mathrm{Co}(\mathbf{1})$ : C, 53.43; $\mathrm{H}, 2.24 ; \mathrm{N}, 15.58$; Found: C, 52.96; H, 2.58; N, 16.01. Selected IR bands $\left(\mathrm{KBr}\right.$ pellet, $\left.\mathrm{cm}^{-1}\right)$ : 1586, 1737, 2070, 2083. UVVis ( $\lambda, \mathrm{nm}$; dimethylformamide): $269,304,316,528$, 623.

The aqueous solution of $\mathrm{Ni}\left(\mathrm{NO}_{3}\right)_{2}(0.290 \mathrm{~g}, 1 \mathrm{mmol})$ in a beaker was mixed with dafone $(0.364 \mathrm{~g}, 2 \mathrm{mmol})$ in methanol slowly. The solid $\mathrm{NH}_{4} \mathrm{NCS}$ (0.152 g, $2 \mathrm{mmol}$ ) was added in portion with continuous

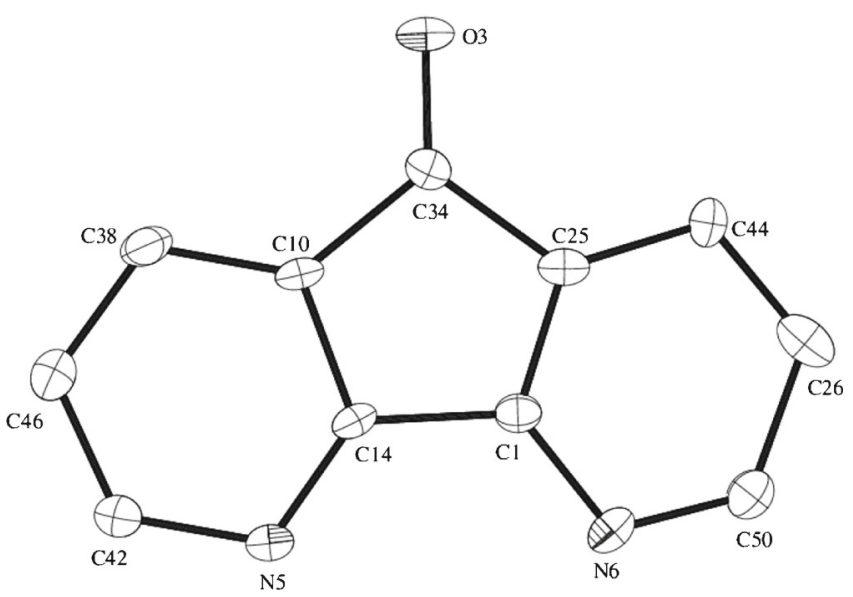

Figure 1. ORTEP of dafone with $20 \%$ ellipsoid probability for all non-hydrogen atoms. stirring. The resultant solution was kept in open air for slow evaporation to obtain green crystals after 7 days. Yield: (based on metal salt) $0.380 \mathrm{~g}(75.00 \%)$. Anal. Calc. for $\mathrm{C}_{24} \mathrm{H}_{12} \mathrm{~N}_{6} \mathrm{O}_{2} \mathrm{~S}_{2} \mathrm{Ni}(2)$ : C, 56.85; H, 2.39; N, 16.58; Found: C, 56.24; H, 2.56; N, 17.15. Selected IR bands (KBr pellet, $\mathrm{cm}^{-1}$ ): 1584, 1638, 1737, 2083, 2097. UV-Vis ( $\lambda$, nm; dimethylformamide): 268,304 , $316,592,660$.

Solid $\mathrm{Zn}(\mathrm{OAc})_{2}(0.219 \mathrm{~g}, 1 \mathrm{mmol})$ and aqueous $\mathrm{NH}_{4} \mathrm{NCS}(0.152 \mathrm{~g}, 2 \mathrm{mmol})$ were consecutively added to methanolic solution of dafone $(0.364 \mathrm{~g}, 2 \mathrm{mmol})$ to get a yellow solution. Light yellow crystals appeared from this solution after a week or so in open air at room temperature. Yield: (based on metal salt) $0.415 \mathrm{~g}$ (76.00\%). Anal. Calc. for $\mathrm{C}_{24} \mathrm{H}_{12} \mathrm{~N}_{6} \mathrm{O}_{2} \mathrm{~S}_{2} \mathrm{Zn}$ (3): C, 52.80; H, 2.22; N, 15.39; Found: C, 52.50; H, 2.13; $\mathrm{N}, 15.82$. Selected IR bands $\left(\mathrm{KBr}\right.$ pellet, $\left.\mathrm{cm}^{-1}\right)$ : 1588 , $1618,1737,2069,2089$. UV-Vis ( $\lambda$, nm; dimethylformamide): 271, 303, 316.

Complex 4 was prepared following the same procedure as for 3. Only $\mathrm{Cd}(\mathrm{OAc})_{2}(0.266 \mathrm{~g}, 1 \mathrm{mmol})$ was used in place of $\mathrm{Zn}(\mathrm{OAc})_{2}$. The proportion of dafone $(0.182 \mathrm{~g}, 1 \mathrm{mmol})$ and $\mathrm{NH}_{4} \mathrm{NCS}(0.152 \mathrm{~g}, 2 \mathrm{mmol})$ was also different. Yield: (based on metal salt) $0.575 \mathrm{~g}$ (70.00\%). Anal. Calc. for $\mathrm{C}_{26} \mathrm{H}_{12} \mathrm{~N}_{8} \mathrm{O}_{2} \mathrm{~S}_{4} \mathrm{Cd}_{2}$ (4): C, 38.01; H, 1.47; N, 13.64; Found: C, 38.95; H, 1.36; $\mathrm{N}, 14.05$. Selected IR bands $\left(\mathrm{KBr}\right.$ pellet, $\left.\mathrm{cm}^{-1}\right)$ : 1586 , $1638,1729,2069$, 2096. UV-Vis ( $\lambda$, nm; dimethylformamide): 269, 304, 316.

\subsection{Physical measurements}

Elemental analyses (carbon, hydrogen and nitrogen) were performed on a Perkin-Elmer 2400 CHNS/O elemental analyser. UV-Vis, IR and fluorescence spectra ( $\mathrm{KBr}$ discs, 4000-300 $\mathrm{cm}^{-1}$ ) were recorded using a Shimadzu UV-Vis 2450 spectrophotometer, Perkin-Elmer FT-IR 0model RX1 spectrometer and Perkin-Elmer LS55 fluorimeter, respectively.

\section{$2.3 X$-ray diffraction}

Single crystals of dafone and 1-4 suitable for Xray crystallographic analysis were selected following examination under a microscope. Diffraction data at room temperature for dafone and $\mathbf{2}$, respectively and for 1, $\mathbf{3}$ and $\mathbf{4}$ were collected on a Bruker SMART APEX II CCD and Bruker-Kappa APEX II CCD diffractometers, respectively using Mo-K $\alpha$ radiation $(\lambda=$ $0.71073 \AA$ ). Crystal data and refinement details are listed in table 1. Dafone was identified as $\mathrm{P} 2{ }_{1} / \mathrm{c}, \mathbf{1 - 3}$ were identified as $\mathrm{Pbcn}$ and $\mathbf{4}$ was identified as Pbca 


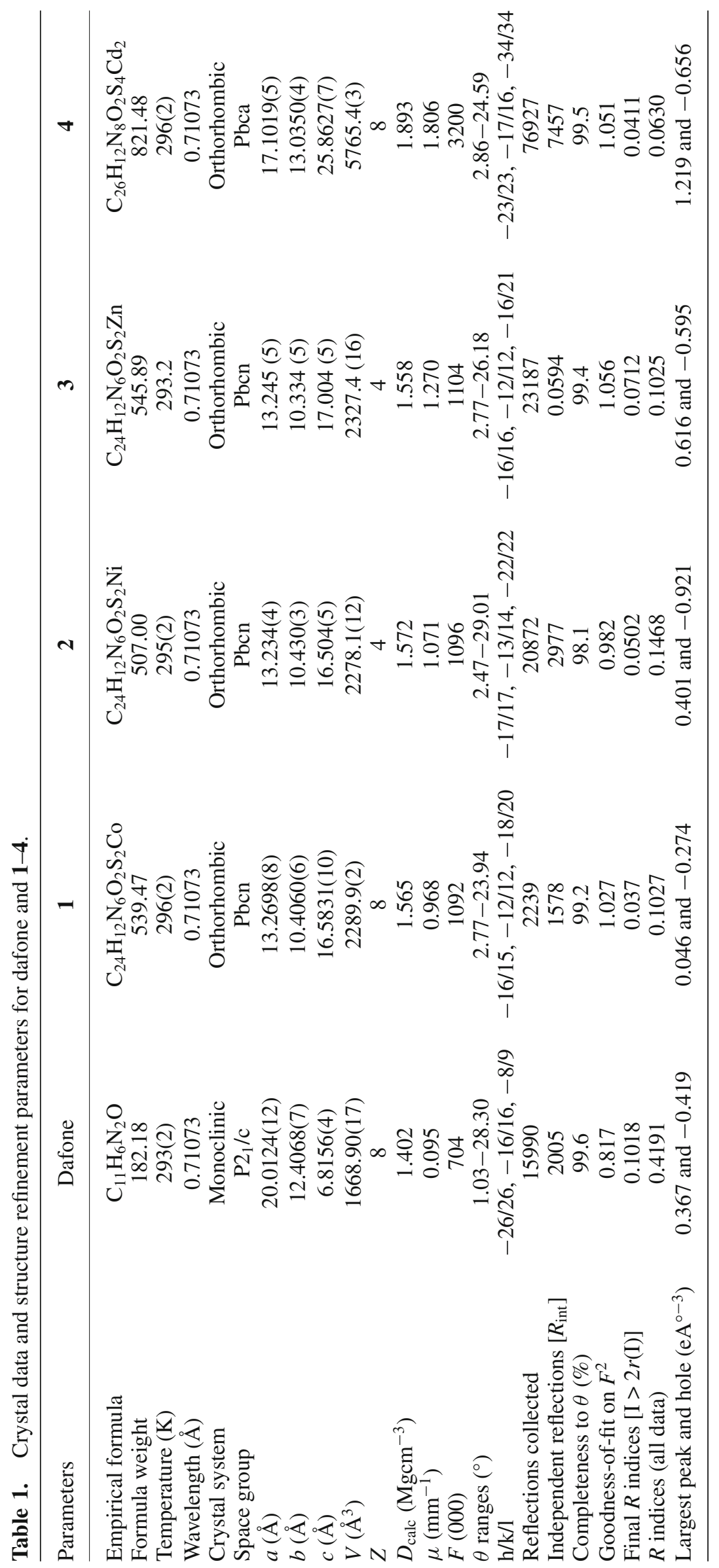


space groups. The structures were solved by direct methods, and the structure solution and refinement were based on $|F|^{2}$. The final differences Fourier map showed the maximum and minimum peak heights at 0.367 and -0.419 for dafone, 0.046 and -0.274 for $1,0.401$ and -0.921 for $2,0.616$ and -0.595 for 3 and 1.219 and -0.656 for 4 with no chemical significance. All calculations were carried out using SHELXL-97 ${ }^{11}$ and ORTEP-32. ${ }^{12}$

\section{Results and discussion}

\subsection{Synthesis and formulation}

Reactions at room temperature with required molar ratio among metal(II) salts, dafone and ammonium thiocyanate in aqueous methanol produce the complexes 14 in good yield. The reactions can be generalized in the following way:

$$
\begin{gathered}
\mathrm{M}(\mathrm{X})_{2 .} p \mathrm{H}_{2} \mathrm{O}+2 \text { dafone }+2 \mathrm{NH}_{4} \mathrm{NCS} \underset{\mathrm{MeOH}}{298 \mathrm{~K}}\left[\mathrm{M}(\text { dafone })_{2}(\mathrm{NCS})_{2}\right]+2 \mathrm{NH}_{4} \mathrm{X}+p \mathrm{H}_{2} \mathrm{O} \ldots \\
(\mathrm{M}=\mathrm{Co}, \mathbf{1} ; \mathrm{Ni}, \mathbf{2} ; \mathrm{Zn}, \mathbf{3}) \\
{\left[\mathrm{M}=\mathrm{Co}(\mathrm{II}), \mathrm{Ni}(\mathrm{II}), \mathrm{Zn}(\mathrm{II}) ; \mathrm{X}=\mathrm{ClO}_{4} \mathrm{NO}_{3}, \mathrm{OAc}, \text { respectively; } p=\text { wholenumber }\right]} \\
\mathrm{Cd}(\mathrm{OAc})_{2 .} 2 \mathrm{H}_{2} \mathrm{O}+\text { dafone }+2 \mathrm{NH}_{4} \mathrm{NCS} \underset{\mathrm{MeOH}}{298 \mathrm{~K}}\left[\mathrm{Cd}(\text { dafone })(\mathrm{NCS})_{2}\right]_{n}+2 \mathrm{NH}_{4} \mathrm{OAc}+2 \mathrm{H}_{2} \mathrm{O} \ldots
\end{gathered}
$$

The complexes were characterized by microanalytical $(\mathrm{C}, \mathrm{H}$ and $\mathrm{N})$, spectroscopic and other physicochemical results. The microanalytical data are in good conformity with the formulations of 1-4 (scheme 1). The moisture insensitive complexes are stable over long periods of time in powdery and crystalline states, and are soluble in dimethyl formamide only, but are insoluble in water, methanol, acetonitrile, etc. In the IR spectra, relatively intense peaks around $1580-1620 \mathrm{~cm}^{-1}$ due to the $\mathrm{C}=\mathrm{N}$ stretching frequency and weak bands in the range of $2980-2900 \mathrm{~cm}^{-1}$ due to the aliphatic $\mathrm{C}-\mathrm{H}$ stretching frequency appear in both the complexes. Characteristic bands for carbonyl in dafone and thiocyanate in complexes appear at $\sim 1720$ and $\sim 2100 \mathrm{~cm}^{-1}$.

\subsection{Description of crystal structure}

3.2a X-ray structures: $\mathrm{X}$-ray crystallographic characterization in each compound results in a distorted
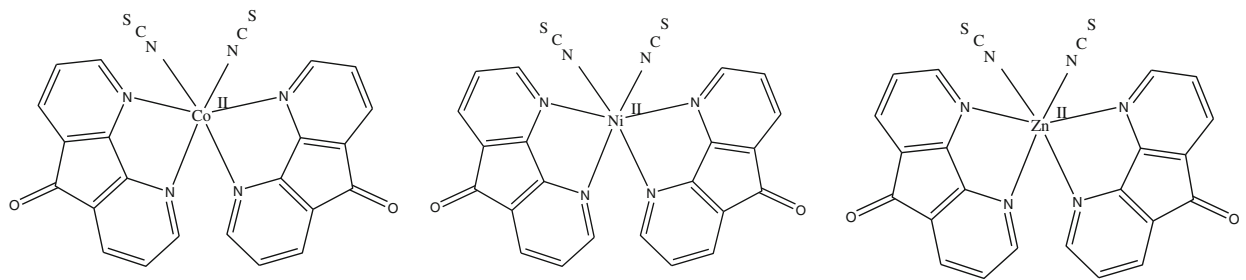

1

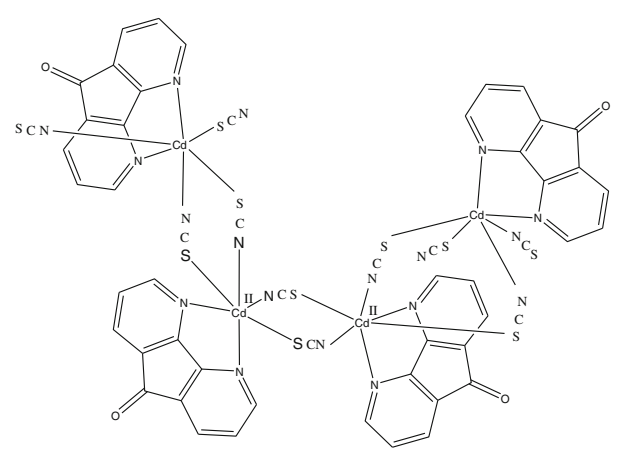

4

Scheme 1. Line drawing structure of complexes 1-4. 
Table 2. Bond angle-bond distance parameters for $\mathbf{1}$.

\begin{tabular}{llll}
\hline $\begin{array}{l}\text { Bond distances } \\
\text { Co(1)-N(1) }\end{array}$ & $2.164(2)$ & $\mathrm{Co}(1)-\mathrm{N}\left(1^{*}\right)$ & $2.264(3)$ \\
$\mathrm{Co}(1)-\mathrm{N}(2)$ & $1.973(2)$ & $\mathrm{Co}(1)-\mathrm{N}\left(2^{*}\right)$ & $2.028(2)$ \\
$\mathrm{Co}(1)-\mathrm{N}(4)$ & $2.131(3)$ & $\mathrm{Co}(1)-\mathrm{N}\left(4^{*}\right)$ & $2.227(2)$ \\
$\mathrm{N}(4)-\mathrm{C}(12)$ & $1.154(3)$ & $\mathrm{C}(12)-\mathrm{S}(2)$ & $1.606(3)$ \\
& & & \\
Bond angles & & & $101.28(9)$ \\
$\mathrm{N}(1)-\mathrm{Co}(1)-\mathrm{N}(2)$ & $79.75(8)$ & $\mathrm{N}(2)-\mathrm{Co}(1)-\mathrm{N}\left(4^{*}\right)$ & $89.28(8)$ \\
$\mathrm{N}(1)-\mathrm{Co}(1)-\mathrm{N}(4)$ & $170.67(9)$ & $\mathrm{N}\left(1^{*}\right)-\mathrm{Co}(1)-\mathrm{N}(4)$ & $101.28(9)$ \\
$\mathrm{N}(1)-\mathrm{Co}(1)-\mathrm{N}\left(1^{*}\right)$ & $86.19(8)$ & $\mathrm{N}\left(2^{*}\right)-\mathrm{Co}(1)-\mathrm{N}(4)$ & $96.33(9)$ \\
$\mathrm{N}(1)-\mathrm{Co}(1)-\mathrm{N}\left(2^{*}\right)$ & $85.93(8)$ & $\mathrm{N}(4)-\mathrm{Co}(1)-\mathrm{N}\left(4^{*}\right)$ & $79.75(8)$ \\
$\mathrm{N}(1)-\mathrm{Co}(1)-\mathrm{N}\left(4^{*}\right)$ & $89.28(8)$ & $\mathrm{N}\left(1^{*}\right)-\mathrm{Co}(1)-\mathrm{N}\left(2^{*}\right)$ & $170.67(9)$ \\
$\mathrm{N}(2)-\mathrm{Co}(1)-\mathrm{N}(4)$ & $91.82(9)$ & $\mathrm{N}\left(1^{*}\right)-\mathrm{Co}(1)-\mathrm{N}\left(4^{*}\right)$ & \\
$\mathrm{N}\left(1^{*}\right)-\mathrm{Co}(1)-\mathrm{N}(2)$ & $85.93(8)$ & $\mathrm{N}\left(2^{*}\right)-\mathrm{Co}(1)-\mathrm{N}\left(4^{*}\right)$ & $91.82(9)$ \\
$\mathrm{N}(2)-\mathrm{Co}(1)-\mathrm{N}\left(2^{*}\right)$ & $160.37(8)$ & & \\
\hline
\end{tabular}

octahedral geometry with two thiocyantes in cis orientation. Owing to the larger chelate bite in dafone than in bpy and phen (free dafone: $3.05 \AA$, bpy: $2.62 \AA$, phen: $2.64 \AA),{ }^{8}$ the complexes form one normal and one larger metal-imine bonds. Each of the crystal structures are described here.

\section{$\left[\mathrm{Co}(\text { dafone })_{2}(\mathrm{NCS})_{2}\right](\mathbf{1})$}

Bond angle-bond distance data (table 2) describes the coordination geometry around $\mathrm{Co}(\mathrm{II})$ in $\mathbf{1}$ as a distorted cis-octahedron (figure 2) with two thiocyanates, where one imine nitrogen $(\mathrm{N} 1 *)$ and one thiocyanato nitrogen $(\mathrm{N} 4 *)$ occupy the axial position. The rest of the imine nitrogens $(\mathrm{N} 1, \mathrm{~N} 2$ and $\mathrm{N} 2 *)$ from two organic ligand units and another thiocyanato nitrogen (N4) occupy equatorial positions. The bond distance ranges in axial and equatorial positions are $0.037 \AA$ and $0.191 \AA$, respectively. Interatomic bond distance data in

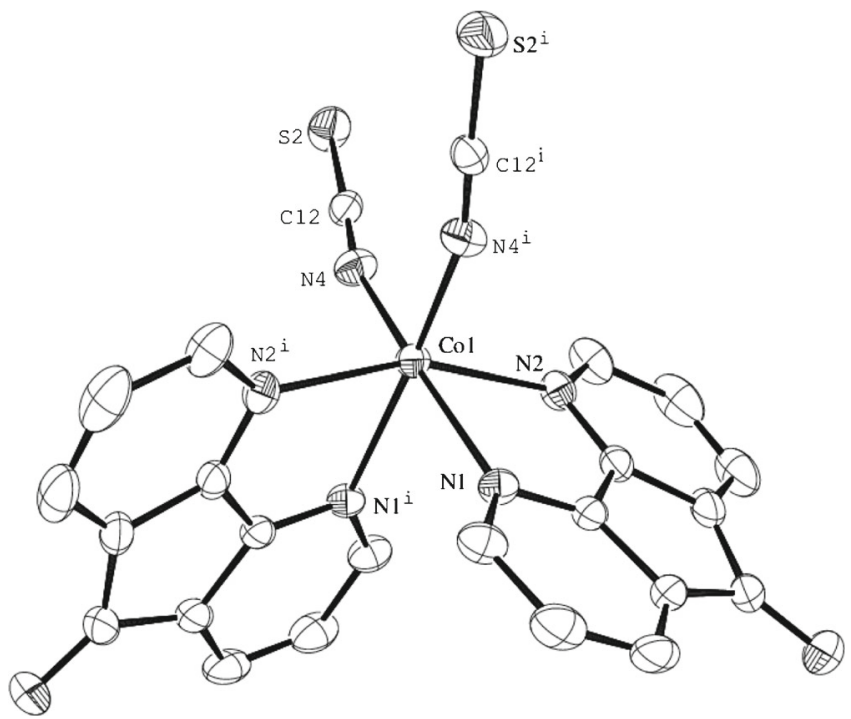

Figure 2. ORTEP of $\mathbf{1}$ with $20 \%$ ellipsoid probability for all non-hydrogen atoms. linear thiocyanate is in good conformity (table $2 ; \mathrm{N}(4)$ $\mathrm{C}(12), 1.154(3) \AA<\mathrm{C}(12)-\mathrm{S}(2), 1.606(3) \AA$ ) with its $\mathrm{N}$ coordination towards $\mathrm{Co}(\mathrm{II})$.

\section{[Ni(dafone $\left.)_{2}(\mathrm{NCS})_{2}\right](2)$}

Structural analysis reveals a distorted cis-octahedral geometry of $\mathbf{2}$ with $\mathrm{Ni}$ (II) at the metal centre (figure 3). According to bond angle-bond distance data (table 3), N7 (imine nitrogen) and N11 (thiocyanato nitrogen) are at axial position. The rest of the coordinating atoms $\mathrm{N}^{*}, \mathrm{~N} 9, \mathrm{~N} 9 *$ (imine nitrogens) and $\mathrm{N} 11^{*}$ (thiocyanato nitrogen) are at the equatorial position. The bond distance ranges in axial and equatorial positions are same $(0.196 \AA)$. N coordination of thiocyanate towards $\mathrm{Ni}(\mathrm{II})$ is confirmed by the shorter $\mathrm{N}-\mathrm{C}$ bond (table 3, 1.152(5) $\AA$ ) than the C-S bond (table 3, 1.618(4) ̊).

\section{$\left[\mathrm{Zn}(\text { dafone })_{2}(\mathrm{NCS})_{2}\right](\mathbf{3})$}

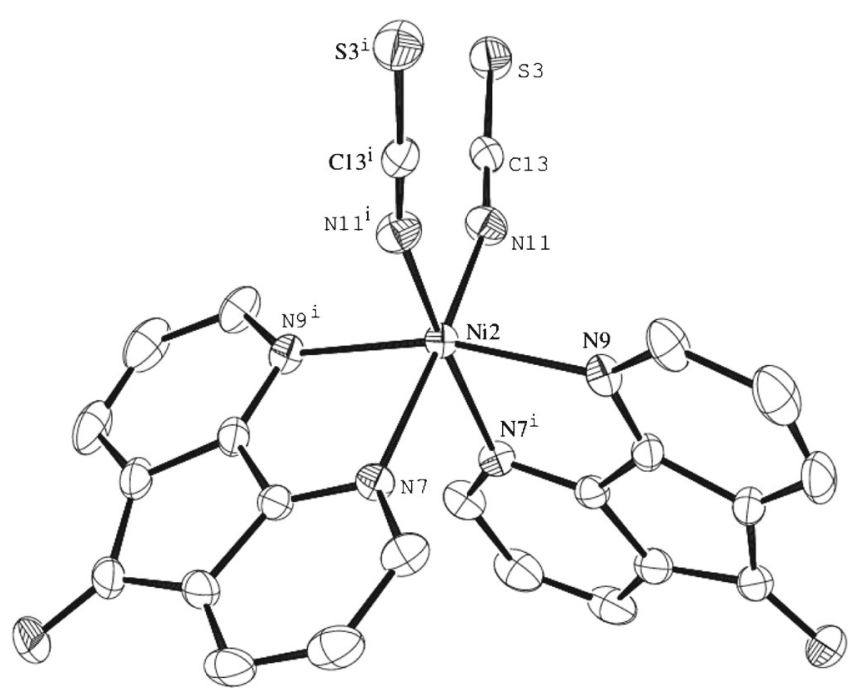

Figure 3. ORTEP of 2 with $20 \%$ ellipsoid probability for all non-hydrogen atoms. 
Table 3. Bond angle-bond distance parameters for 2.

\begin{tabular}{llll}
\hline Bond distances & & & \\
$\mathrm{Ni}(2)-\mathrm{N}\left(11^{*}\right)$ & $1.997(4)$ & $\mathrm{Ni}(2)-\mathrm{N}(9)$ & $2.172(3)$ \\
$\mathrm{Ni}(2)-\mathrm{N}(11)$ & $1.997(4)$ & $\mathrm{Ni}(2)-\mathrm{N}\left(7^{*}\right)$ & $2.193(3)$ \\
$\mathrm{Ni}(2)-\mathrm{N}\left(9^{*}\right)$ & $2.172(3)$ & $\mathrm{Ni}(2)-\mathrm{N}(7)$ & $2.193(3)$ \\
$\mathrm{N}(11)-\mathrm{C}(13)$ & $1.152(5)$ & $\mathrm{C}(13)-\mathrm{S}(3)$ & $1.618(4)$ \\
$\mathrm{N}(11)-\mathrm{C}(13)$ & $1.152(5)$ & $\mathrm{C}(13)-\mathrm{S}(3)$ & $1.618(4)$ \\
& & & \\
Bond angles & & & $86.79(11)$ \\
$\mathrm{N}\left(11^{*}\right)-\mathrm{Ni}(2)-\mathrm{N}(11)$ & $93.8(2)$ & $\mathrm{N}\left(9^{*}\right)-\mathrm{Ni}(2)-\mathrm{N}(7 *)$ & $82.08(12)$ \\
$\mathrm{N}\left(11^{*}\right)-\mathrm{Ni}(2)-\mathrm{N}(9 *)$ & $98.65(13)$ & $\mathrm{N}(9)-\mathrm{Ni}(2)-\mathrm{N}(7 *)$ & $89.78(13)$ \\
$\mathrm{N}(11)-\mathrm{Ni}(2)-\mathrm{N}\left(9^{*}\right)$ & $91.85(14)$ & $\mathrm{N}(11 *)-\mathrm{Ni}(2)-\mathrm{N}(7)$ & $82.08(12)$ \\
$\mathrm{N}(11 *)-\mathrm{Ni}(2)-\mathrm{N}(9)$ & $91.85(14)$ & $\mathrm{N}(11)-\mathrm{Ni}(2)-\mathrm{N}(7)$ & $87.79(11)$ \\
$\mathrm{N}(11)-\mathrm{Ni}(2)-\mathrm{N}(9)$ & $98.65(13)$ & $\mathrm{N}\left(9^{*}\right)-\mathrm{Ni}(2)-\mathrm{N}(7)$ & \\
$\mathrm{N}(9 *)-\mathrm{Ni}(2)-\mathrm{N}(9)$ & $164.63(18)$ & $\mathrm{N}(9)-\mathrm{Ni}(2)-\mathrm{N}(7)$ & \\
$\mathrm{N}\left(11^{*}\right)-\mathrm{Ni}(2)-\mathrm{N}\left(7^{*}\right)$ & $173.35(13)$ & $\mathrm{N}(7 *)-\mathrm{Ni}(2)-\mathrm{N}(7)$ & $87.16(15)$ \\
$\mathrm{N}(11)-\mathrm{Ni}(2)-\mathrm{N}(7 *)$ & $89.78(13)$ & & \\
\hline
\end{tabular}

Table 4. Bond angle-bond distance parameters for 3.

\begin{tabular}{llll}
\hline Bond distances & & & \\
$\mathrm{Zn}(1)-\mathrm{N}(1)$ & $2.193(5)$ & $\mathrm{Zn}(1)-\mathrm{N}\left(1^{*}\right)$ & $2.193(5)$ \\
$\mathrm{Zn}(1)-\mathrm{N}(2)$ & $2.353(5)$ & $\mathrm{Zn}(1)-\mathrm{N}\left(2^{*}\right)$ & $2.353(5)$ \\
$\mathrm{Zn}(1)-\mathrm{N}(3)$ & $2.007(6)$ & $\mathrm{Zn}(1)-\mathrm{N}\left(3^{*}\right)$ & $2.007(6)$ \\
$\mathrm{N}(3)-\mathrm{C}(12)$ & $1.154(8)$ & $\mathrm{C}(12)-\mathrm{S}(1)$ & $1.604(8)$ \\
& & & \\
Bond angles & & & \\
$\mathrm{N}(1)-\mathrm{Zn}(1)-\mathrm{N}(2)$ & $76.47(18)$ & $\mathrm{N}(3)-\mathrm{Zn}(1)-\mathrm{N}\left(3^{*}\right)$ & $98.9(3)$ \\
$\mathrm{N}(1)-\mathrm{Zn}(1)-\mathrm{N}(3)$ & $103.1(2)$ & $\mathrm{N}\left(1^{*}\right)-\mathrm{Zn}(1)-\mathrm{N}(2)$ & $85.21(18)$ \\
$\mathrm{N}(1)-\mathrm{Zn}(1)-\mathrm{N}\left(1^{*}\right)$ & $155.1(3)$ & $\mathrm{N}\left(1^{*}\right)-\mathrm{Zn}(1)-\mathrm{N}(3)$ & $93.1(2)$ \\
$\mathrm{N}(1)-\mathrm{Zn}(1)-\mathrm{N}\left(2^{*}\right)$ & $85.21(18)$ & $\mathrm{N}\left(1^{*}\right)-\mathrm{Zn}(1)-\mathrm{N}\left(2^{*}\right)$ & $76.47(18)$ \\
$\mathrm{N}(1)-\mathrm{Zn}(1)-\mathrm{N}\left(3^{*}\right)$ & $93.1(2)$ & $\mathrm{N}\left(1^{*}\right)-\mathrm{Zn}(1)-\mathrm{N}\left(3^{*}\right)$ & $103.1(2)$ \\
$\mathrm{N}(2)-\mathrm{Zn}(1)-\mathrm{N}(3)$ & $88.7(2)$ & $\mathrm{N}\left(2^{*}\right)-\mathrm{Zn}(1)-\mathrm{N}(3)$ & $168.3(2)$ \\
$\mathrm{N}(2)-\mathrm{Zn}(1)-\mathrm{N}\left(2^{*}\right)$ & $85.3(2)$ & $\mathrm{N}\left(2^{*}\right)-\mathrm{Zn}(1)-\mathrm{N}\left(3^{*}\right)$ & $88.7(2)$ \\
$\mathrm{N}(2)-\mathrm{Zn}(1)-\mathrm{N}\left(3^{*}\right)$ & $168.3(2)$ & & \\
\hline
\end{tabular}

Considering bond angle-bond distance parameters (table 4), the distorted octahedral geometry of $\mathbf{3}$ (figure 4) consists of two imine nitrogens (N1, N1*), each from two different dafone units in the axial position. The other two imine nitrogens $\mathrm{N} 2$ and N2* from two different dafone ligands and the two thiocyanato nitrogens N3 and N3* are in equatorial position. The bond distance ranges in the axial and equatorial positions are zero and $0.346 \AA$, respectively. The shorter N-C bond ([table 4, 1.154(8) $\AA$ ] than the C-S bond [table $4,1.604(8) \AA]$ ) in the coordinated thiocyanate confirms $\mathrm{N}$ coordination in the complex.

\section{$\left[\mathrm{Cd}(\text { dafone })(\mathrm{NCS})_{2}\right]_{n}(\mathbf{4})$}

From bond angle-bond distance data (table 5), the molecular structure of a mononuclear unit in $\mathbf{4}$ is described as distorted octahedron (figure 5) with two thiocyanato sulphurs (S1 and S2) at axial position, and two imine nitrogens ( $\mathrm{N} 1$ and N2) from the ligand moiety, two nitrogens (N5 and N7) from two different

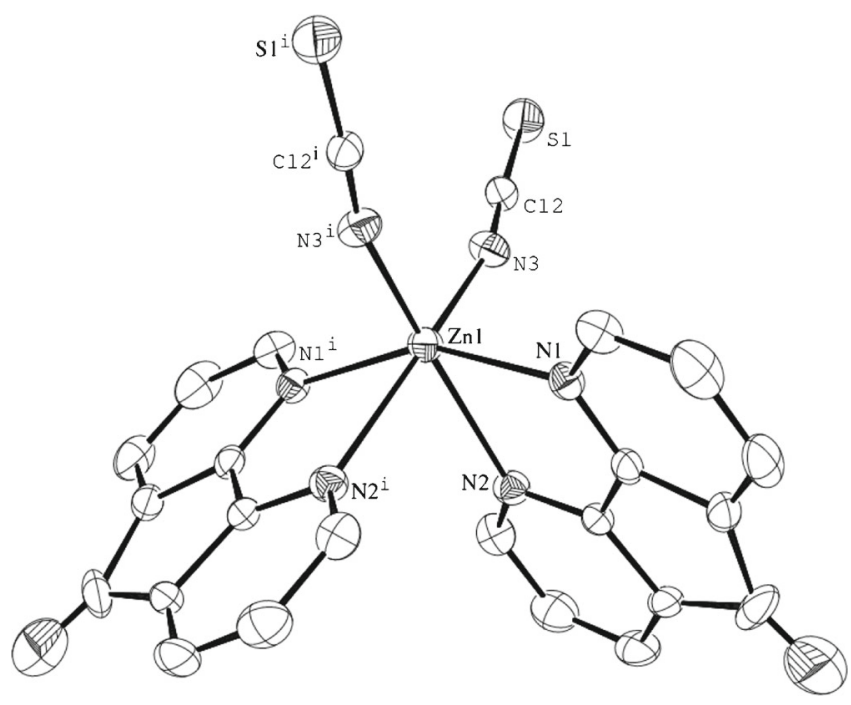

Figure 4. ORTEP of $\mathbf{3}$ with $20 \%$ ellipsoid probability for all non-hydrogen atoms.

thiocyanates occupy the equatorial position. Ambidentate thiocyanates are end-end bridged with the next 
Table 5. Bond angle-bond distance parameters for 4 .

\begin{tabular}{llll}
\hline Bond distances & & & \\
Cd(1)-N(1) & $2.447(3)$ & $\mathrm{Cd}(1)-\mathrm{S}(1)$ & $2.7587(10)$ \\
Cd(1)-N(2) & $2.417(3)$ & $\mathrm{Cd}(1)-\mathrm{S}(2)$ & $2.7421(10)$ \\
Cd(1)-N(5) & $2.250(3)$ & & \\
Cd(1)-N(7) & $2.241(3)$ & & \\
& & & \\
Bond angles & & & $87.67(7)$ \\
$\mathrm{N}(1)-\mathrm{Cd}(1)-\mathrm{N}(2)$ & $74.48(10)$ & $\mathrm{N}(2)-\mathrm{Cd}(1)-\mathrm{S}(2)$ & $100.73(16)$ \\
$\mathrm{N}(1)-\mathrm{Cd}(1)-\mathrm{N}(5)$ & $90.71(13)$ & $\mathrm{N}(5)-\mathrm{Cd}(1)-\mathrm{N}(7)$ & $93.30(9)$ \\
$\mathrm{N}(1)-\mathrm{Cd}(1)-\mathrm{N}(7)$ & $168.55(14)$ & $\mathrm{N}(5)-\mathrm{Cd}(1)-\mathrm{S}(1)$ & $92.08(9)$ \\
$\mathrm{N}(1)-\mathrm{Cd}(1)-\mathrm{S}(1)$ & $89.74(7)$ & $\mathrm{N}(5)-\mathrm{Cd}(1)-\mathrm{S}(2)$ & $89.21(10)$ \\
$\mathrm{N}(1)-\mathrm{Cd}(1)-\mathrm{S}(2)$ & $85.84(7)$ & $\mathrm{N}(7)-\mathrm{Cd}(1)-\mathrm{S}(1)$ & $173.07(3)$ \\
$\mathrm{N}(2)-\mathrm{Cd}(1)-\mathrm{N}(5)$ & $165.17(13)$ & $\mathrm{N}(7)-\mathrm{Cd}(1)-\mathrm{S}(2)$ & \\
$\mathrm{N}(2)-\mathrm{Cd}(1)-\mathrm{N}(7)$ & $94.07(14)$ & $\mathrm{S}(1)-\mathrm{Cd}(1)-\mathrm{S}(2)$ & \\
$\mathrm{N}(2)-\mathrm{Cd}(1)-\mathrm{S}(1)$ & $86.01(7)$ & & \\
\hline
\end{tabular}

$\mathrm{Cd}(\mathrm{II})$ centre. Bond distance ranges in the axial and equatorial positions are $0.0163 \AA$ and $0.197 \AA$, respectively.

Owing to the larger chelate bite, as stated earlier, it will be found from tables $2-5$ that one of the metalimine distances for a single bidentate dafone $\operatorname{Co}(1)$ $\mathrm{N}(1), \mathrm{Ni}(2)-\mathrm{N}(7), \mathrm{Zn}(1)-\mathrm{N}(2), \mathrm{Cd}(2)-\mathrm{N}(1)$ is larger than the other $\mathrm{Co}(1)-\mathrm{N}(2), \mathrm{Ni}(2)-\mathrm{N}\left(9^{*}\right), \mathrm{Zn}(1)-\mathrm{N}(1), \mathrm{Cd}(1)-$ $\mathrm{N}(2)$, respectively.
In case of 3, hard $\mathrm{N}$ donors from dafone (the organic ligand backbone) make the borderline $\mathrm{Zn}$ (II) hard. Hence, $\mathrm{N}$ ends of NCS coordinate to Zn(II) making it a mononuclear complex with no $\mathrm{S}$ coordination. But for 4, hard $\mathrm{N}$ donors from dafone do not increase hardness of the soft $\mathrm{Cd}(\mathrm{II})$ centre to that extent so that coordination with further $\mathrm{N}$ donor site(s) is possible. Rather, the soft $\mathrm{S}$ centre from another NCS unit binds to the $\mathrm{Cd}(\mathrm{II})$ centre. The $\mathrm{N}$ end of one NCS and $\mathrm{S}$ end of

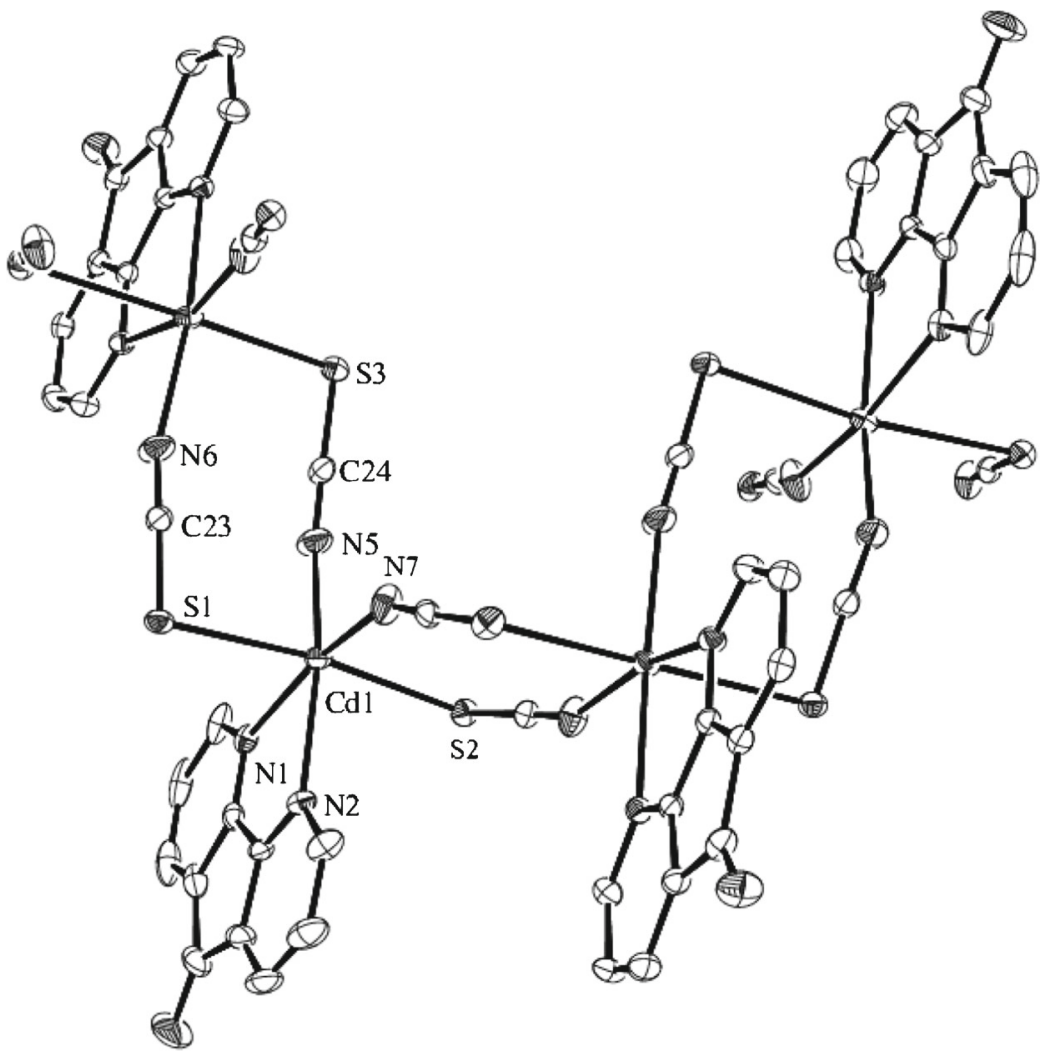

Figure 5. ORTEP of $\mathbf{4}$ with $20 \%$ ellipsoid probability for all non-hydrogen atoms. 


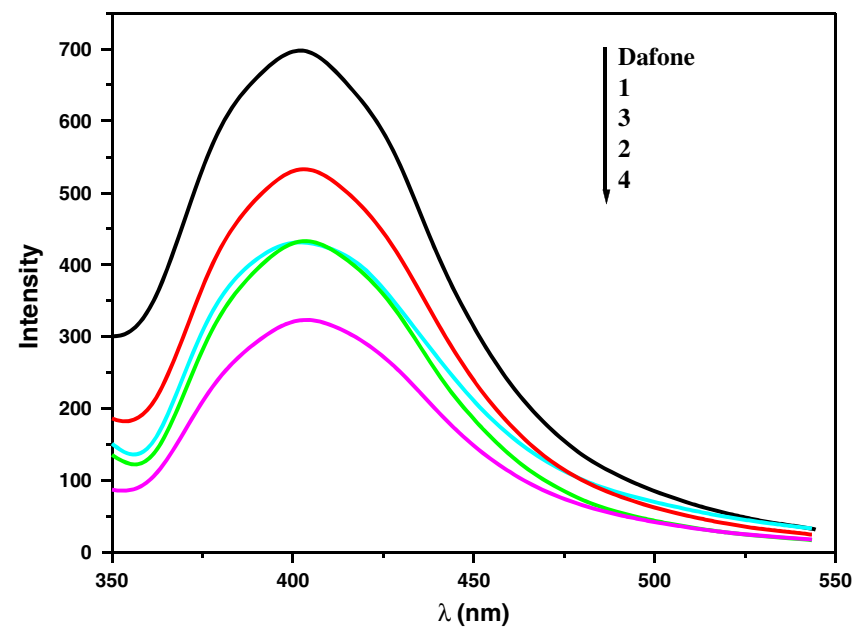

Figure 6. Room temperature steady-state emission of free ligand (dafone) and metal complexes.

the another NCS unit coordinate to other $\mathrm{Cd}$ (dafone $)_{2}$ moieties forming a coordination polymer.

\subsection{Emission properties}

A few reports on photophysical properties of metal bound dafone are available. ${ }^{8 b, 10,13}$ Free dafone in dimethyl formamide shows emission band at $402 \mathrm{~nm}$ (figure 6) at room temperature when excited at $332 \mathrm{~nm}$. Absorption bands of compounds $\mathbf{1}$ and $\mathbf{2}$ are assigned as spin allowed and that of $\mathbf{3}$ and $\mathbf{4}$ are intraligand transitions ${ }^{14}$ (figures S1-S4, Supplementary file). All its complexes (1-4) show broad emission band (excitations at 332, 335, 336 and 334, respectively) in dimethyl formamide at about same wavelength as in dafone indicating charge transfer nature of transition. ${ }^{15}$ Quenching of fluorescence of an organic moiety (ligand) by its complexation with transition metal ions is a common phenomenon, ${ }^{16}$ which is explained by the process of magnetic perturbation, redox activity, electronic energy transfer, etc. Moreover, increasing spin-orbit coupling with heavier atoms relaxes the spin selection rule for radiative and radiationless transitions of the metal complexes resulting in quenching the emission intensity of lowest excited state. ${ }^{17}$ All these physical phenomena are responsible for fluorescence intensity quenching in our complexes.

\section{Conclusion}

We have synthesized and crystallographically characterized four metal complexes of $\mathrm{Co}(\mathrm{II}), \mathrm{Ni}(\mathrm{II}), \mathrm{Zn}$ (II) and $\mathrm{Cd}(\mathrm{II})$ in combination with dafone and thiocyanate. In each case, the complexes form cis isomer which is in good agreement with the previously reported compounds. ${ }^{8,9}$ The room temperature steadystate emission of dafone is quenched in its complexes which are also in good conformity with the standard theories of spin-orbit coupling, magnetic perturbation, redox activity, electronic energy transfer, etc.

\section{Supplementary information}

CCDC Nos. 941025, 941023 and 941024 contain supplementary crystallographic data for $\mathbf{1}, 3$ and $\mathbf{4}$, respectively. These data can be obtained free of charge via http://www.ccdc.cam.ac.uk/conts/retrieving.html, or from the Cambridge Crystallographic Data Centre, 12 Union Road, Cambridge CB2 1EZ, UK; fax: $(+44)$ 1223-336-033; or e-mail: deposit@ccdc.cam.ac.uk. Supplementary figures S1-S4 can be seen in www.ias. ac.in/chemsci.

\section{Acknowledgements}

RG gratefully acknowledges the Department of Science and Technology (DST), New Delhi, India (F. No. SR/FT/CS-83/2010 dt. 11-02-2011) for financial assistance. MM is thankful to the University of Burdwan for her research fellowship.

\section{References}

1. (a) Comba P and Hambley P W 2009 Molecular modeling of inorganic compounds, third ed., Wiley- $\mathrm{VCH}$, Weinheim; (b) Steed J W and Atwood J L 2009 Supramolecular chemistry, 2nd edn. New York: John Wiley \& Sons

2. (a) Li Y, Soe C M, Wilson J J, Tuang S L, Apfel U-P and Lippard S J 2013 Eur. J. Inorg. Chem. XX 2011; (b) Alexandropoulos D I, Manos M J, Papatriantafyllopoulou C, Mukherjee S, Tasiopoulos A J, Perlepes S P, Christou G and Stamatatos T C, 2012 Dalton Trans. 41 4744; (c) Banerjee S, Prasad P and Hussain A, Khan I, Kondaiah P and Chakravarty A R 2012 Chem. Commun. 487702

3. (a) Kaes C, Katz A and Hosseini M W 2000 Chem. Rev. 100 3553; (b) Ishiyama T, Takagi J, Hartwig J F and Miyaura N 2002 Angew. Chem. Int. Ed. 41 3056; (c) Miao W, Choi J-P and Bard A J 2002 J. Am. Chem. Soc. 124 14478; (d) Kusukawa T and Fujita M 2002 J. Am. Chem. Soc. 124 13576; (e) Go Y B, Wang X, Anokhina E V and Jacobson A J 2005 Inorg. Chem. 448265

4. (a) Sammes P G and Yahioglu G 1994 Chem. Soc. Rev. 23 327; (b) Binnemans K, Lenaerts P, Driesen K and Walrand C G 2004 J. Mat. Chem. 14 191; (c) Wan Y, Zhang L, Jin L, Gao S and Lu S 2003 Inorg. Chem. 42 4985; (d) Kim Y, Lee H, Dutta P K and Das A 2003 Inorg. Chem. 42 4215; (e) Biswas B, Pal A, Mitra P, Tuna F, Mukherjee M and Ghosh R 2012 J. Coord. Chem. $\mathbf{6 5} 4067$ 
5. (a) Zhang H, Wang X, Zhang K and Teo B K 1999 Coord. Chem. Rev. 183 157; (b) Brewster T P, Ding W, Schley N D, Hazari N, Batista V S and Crabtree R H, 2011 Inorg. Chem. 50 11938; (c) Das S, Bhar K, Chattopadhyay S, Mitra P, Smith V J, Barbour L J and Ghosh B K 2012 Polyhedron 38 26; (d) Rao A S, Pal A, Ghosh R and Das S K 2009 Inorg. Chem. 48 1802

6. (a) Biswas B, Raghavaiah P, Aliaga-Alcalde N, Chen J-D and Ghosh R 2010 Polyhedron 29 2716; (b) Biswas B, Pal A, Rama Krishna G, Reddy C M, Tuna F and Ghosh R 2011 Polyhedron 30 2032; (c) Pal A, Biswas B, Mondal S K, Lin C-H and Ghosh R 2012 Polyhedron 31 671; (d) Biswas B, Mitra M, Adhikary J, Krishna G R, Bag P P, Reddy C M, Aliaga-Alcalde N, Chattopadhyay N T, Das D and Ghosh R 2013 Polyhedron 53264

7. Ravikumar K and Lakshmi N V 1994 Z. Kristallogr. 209 56

8. (a) Babu B K, Elahi S M, Chary T K and Rajasekharan M V 2011 Indian J. Chem. 50A 1318; (b) Machura B, Wolff M, Palion J, Witlicka A S, Nawrot I and Michalik K 2011 Struct. Chem. 22 1053; (c) Maguire L, Seward C M, Baljak S, Rumann T, Ortin Y, Banide E, Niktin K, Buntz M H and Mcglinchey M J 2009 Eur. J. Inorg. Chem. 3250

9. (a) Menon S and Rajasekharan M V 1996 Inorg. Chem. 36 4983; (b) Menon S and Rajasekharan M V
1998 Polyhedron 17 2463; (c) Balagopalakrishna C, Rajasekharan M V, Bott S, Atwood J L and Ramakrishna B L, 1992 Inorg. Chem. 31 2843; (d) Lu Z, Duan C, Tian Y, You X, 1996 Inorg. Chem. 352253

10. Henderson Jr L J, Fronczek F R and Cherry W R 1984 J. Am. Chem. Soc. 1065876

11. Bruker 2007 SMART, SAINT and SADABS. Bruker AXS Inc., Madison, Wisconsin, USA

12. Sheldrick G M 1999 SHELXL-97, University of Göttingen, Göttingen, Germany

13. Zhang L and Li B 2009 Inorg. Chim. Acta. 3624857

14. (a) Lever A B P 1984 Inorganic Electronic Spectroscopy, 2nd Edn, Amstardam: Elsevier Publishers; (b) Sole J G, Bausa L E and Jaque D 2005 An introduction to the optical spectroscopy of inorganic solids, John Wiley \& Sons, New York; (c) Majumder A, Rosair G M, Mallick A, Chattopadhyay N and Mitra S 2006 Polyhedron 251753

15. Majumder A, Rosair G M, Mallick A, Chattopadhyay N and Mitra S 2006 Polyhedron 251753

16. (a) Varnes A W, Dodson R B and Wehry E L,1972 J. Am. Chem. Soc. 94 946; (b) Kemlo J A and Sheperd T M 1977 Chem. Phys. Lett. 47158

17. (a) Harriman A $1981 \mathrm{~J}$. Chem. Soc. Faraday Trans. 2 77 1281; (b) Prodi A, Kleverlaan C J, Indelli M T, Scandola F, Alessio E and Iengo E 2001 Inorg. Chem. 40 3498 